\title{
TRABALHO REPRODUTIVO NO BRASIL: QUEM FAZ?*
}

\author{
Hildete Pereira de Melo ${ }^{* *}$
}

\author{
Marta Castilho
}

RESUMO Este artigo tem como objetivo analisar quem são as pessoas que realizam as tarefas de reprodução social sem remuneração, de enorme importância na reprodução da vida e no bem-estar da sociedade. Esses serviços são realizados majoritariamente por mulheres, e por não gerarem renda, têm contribuído para reforçar a subestimação das atividades realizadas por elas na sociedade. Este artigo tem como objetivo desvelar essa questão, através da análise do trabalho reprodutivo feminino, a partir dos microdados da PNAD/IBGE. Quem são? Quanto tempo dedicam a essas tarefas as pessoas que realizam o trabalho reprodutivo? Nossos resultados indicam que, sejam analfabetas ou tenham educação superior, seja qual for o tipo de contrato que possuam no emprego, sejam ocupadas ou estejam fora do mercado de trabalho, todas as mulheres têm uma carga elevada na execução desses trabalhos.

Palavras-chave: trabalho reprodutivo; afazeres domésticos; invisibilidade do trabalho feminino

Código JEL: J16

\footnotetext{
* Artigo recebido em 21 de junho de 2007 e aprovado em 16 de fevereiro de 2009. Este artigo foi preparado para o projeto "Comercio, género y equidad en América Latina: generando conocimiento para la acción política", conduzido pelo capítulo latino-americano da Rede Internacional de Comércio e Gênero (IGTN-LA), com o apoio financeiro do International Development Research Centre (IDRC-Canadá).

** Professora associada da Faculdade de Economia, coordenadora do Núcleo Transdisciplinar de Estudos de Gênero (NUTEG) e editora da revista Gênero da Universidade Federal Fluminense (UFF), e-mail: hildete@economia.uff.br

*** Professora adjunta e coordenadora da Pós-graduação da Faculdade de Economia da Universidade Federal Fluminense, e-mail: castilho@economia.uff.br
} 


\section{WHO DOES REPRODUCTIVE WORK IN BRAZIL?}

ABSTRACT This paper aims to analyse who are the people who do unpaid tasks for social reproduction, central to reproduction of life and of societal well-being. These jobs are mostly done by women and, since they do not generate income, have reinforced the underestimate women's activities in society. This paper aims to unveil this issue through the analysis of female reproductive work, based on micro-data from PNAD/IBGE. Who are the people doing reproductive work, and how much time they devote to these tasks? Our results indicate that, whether illiterate or college graduates, whatever the type of employment contract they have, whether occupied or out of the labour market, all women take a heavy load in the execution of these tasks.

Key words: reproductive work; invisibility of female work 


\section{INTRODUÇÃO}

As condições de vida de mulheres e homens não são produtos de um destino biológico, mas, sim, fruto de construções sociais que têm como base material o trabalho e se exprimem através de uma divisão social do trabalho entre os sexos. Essa divisão sexual do trabalho reflete o fato que a maioria dos homens exerce suas atividades no mercado de trabalho capitalista (o chamado "trabalho produtivo") e as mulheres dividem seu tempo "naturalmente" entre a produção de mercadorias fora de casa e a realização das tarefas domésticas relativas aos cuidados da família (o dito "trabalho reprodutivo").

$\mathrm{O}$ trabalho reprodutivo tem um grande significado para o bem-estar do ser humano. Porém, como não tem caráter mercantil, é ignorado pelas ciências econômicas e desvalorizado pela sociedade, que dele depende para se reproduzir. Assim, a divisão sexual do trabalho está no cerne da argumentação do pensamento feminista sobre as diferenças entre o papel feminino e o masculino.

O objetivo deste estudo é analisar o trabalho reprodutivo debatendo sua importância econômica e a partir das informações estatísticas disponíveis para o ano 2005, descrever quem o executa na sociedade brasileira. Para isso, o artigo apresenta, uma discussão no campo das ciências econômicas sobre a contribuição do trabalho reprodutivo para a sociedade. Em seguida mostra quem são os homens e mulheres (sobretudo) que fazem as tarefas domésticas - analisando seu nível de educação, tipo de contrato de trabalho, setor em que se encontram, entre outros. São analisadas em separado aquelas pessoas consideradas estatisticamente como "inativas", dentre as quais se encontra o grande contingente das intituladas donas de casa. Espera-se com essas reflexões contribuir para o avanço da temática da invisibilidade do trabalho reprodutivo e dessa forma colaborar para seu reconhecimento na sociedade.

\section{O SIGNIFICADO “ECONÔMICO" DO TRABALHO REPRODUTIVO}

Nos últimos 40 anos, o movimento internacional de mulheres possibilitou o avanço da produção acadêmica feminista e a emergência de fundamentos teóricos para interpretar a histórica discriminação das mulheres. 
Muitos estudos feministas questionaram os paradigmas científicos do mito da neutralidade da ciência e as teorias deterministas biológicas que fazem uma leitura biológica e naturalizante da condição feminina (Beauvoir, 1949; Aguiar, 1997). Naquela produção acadêmica, as mulheres apareciam como uma mera categoria estatística, no âmbito da estratificação social limitada aos estudos sobre a família, nos quais as mulheres reinam. A família é considerada uma estrutura que atravessa a história, linear na sua evolução e perene quanto à composição de seus membros. Dessa nova percepção feminista surge o conceito de gênero, que propõe uma construção histórica e social dos papéis feminino e masculino para explicar as relações sociais entre os sexos, vividas na sociedade com forte assimetria. ${ }^{1}$ A partir dessa abordagem, transversal e multidisciplinar, desenha-se um quadro geral do papel feminino na sociedade, que possibilita a recuperação daquelas atividades ignoradas pela lógica do mundo capitalista.

Assim, na atualidade emergiu uma pluralidade de enfoques e o feminismo aparece tanto como pensamento crítico quanto atividade política. Essa diversidade e pluralidade entre teoria e metodologia dos diversos "feminismos" expressam a complexidade desse campo científico, assim como as dificuldades da articulação entre o movimento social e a formulação de políticas públicas.

O novo olhar feminista tem como uma das temáticas recorrentes a invisibilidade do trabalho da mulher, que está profundamente ligada à desqualificação do trabalho doméstico e à inferioridade feminina. Esse é um dos temas mais antigos trazidos pelo feminismo para as ciências sociais e tem pautado a tentativa de reinterpretar os conceitos de trabalho doméstico e trabalho produtivo/improdutivo.

Sobre a importante questão de por que o trabalho doméstico é executado predominantemente por mulheres as diversas ciências sociais, sobretudo a teoria econômica per se, têm pouco ou nada a dizer (Melo e Pena, 1985; Melo e Serrano, 1997). No caso da economia, as análises sobre bem-estar humano normalmente se restringem à produção mercantil de bens e serviços, negligenciando os demais aspectos materiais e imateriais que garantem a reprodução humana. São quase inexistentes os estudos sistemáticos das atividades relativas ao bem-estar humano $\mathrm{e}$ às necessidades das pessoas, $\mathrm{e}$ que tratam de questões como: a reprodução dos seres humanos, o trabalho 
doméstico, a socialização das crianças e o cuidado com os idosos e doentes (tarefas típicas femininas). Essas tarefas, que antes eram organizadas por meio de relações de parentesco e inseparáveis em relação a sexo e classe, são, na sociedade capitalista, tratadas separadamente e mantêm íntima relação com a situação de inferioridade da mulher no mundo atual.

Por sua vez, a utilização do conceito de divisão sexual do trabalho, consolidado desde a industrialização, possibilita a subestimação das atividades realizadas pelas mulheres na família. Essas atividades são consideradas como não-trabalho, porque se confundem "produção" com "produção de mercadorias" e "trabalho" com “emprego". Essa percepção embute uma associação linear entre a atividade masculina e a produção mercantil e a feminina e a atividade familiar doméstica. Para as feministas, essa associação evidencia a invisibilidade do trabalho das mulheres.

Todavia, ao longo destas últimas décadas houve uma transformação no papel feminino: a participação das mulheres no mercado de trabalho é crescente e houve maior acesso à escolaridade feminina (o que provocou, entre outros, uma mudança nos arranjos familiares, tais como a redução do tamanho das famílias e quebra do modelo patriarcal). ${ }^{2}$ Ainda assim, as ciências econômicas continuam a não dar conta da questão da invisibilidade do trabalho reprodutivo. $\mathrm{O}$ desconhecimento da especificidade da contribuição das mulheres acentuou a subestimação das práticas por elas exercidas no espaço familiar e no produtivo, reforçando a ideia do subemprego feminino. Ester Boserup (1970) afirmou, de maneira pioneira, que a divisão sexual do trabalho é um elemento de base na divisão do trabalho e responsável pela invisibilidade. ${ }^{3}$ A autora apontou como exemplo a contabilidade do produto nacional: nesta, a produção e os serviços de subsistência, as atividades realizadas pelas mulheres e suas contribuições ao bem-estar socioeconômico são subestimados ou a eles não se dá devida importância (seção 1.1).

As críticas formuladas pelas feministas acadêmicas a essa invisibilidade do trabalho feminino ajudaram a ampliar a discussão sobre as formas de valorizar o papel das mulheres nas duas instâncias sociais: a reprodução e a produção. Esse enfoque evidencia que a plena participação das mulheres pode ser visualizada através da eliminação das limitações que as marginalizam ou as tornam invisíveis, seja nas atividades domésticas, seja nas atividades públicas e produtivas. Esses estudos explicitaram a desigualdade exis- 
tente na relação do trabalho do homem ao trabalho produtor de mercadorias e a da mulher à casa e concluíram que o termo "dona de casa" não pode ser sinônimo de esposa e mãe, mas, sim, de trabalho doméstico não remunerado (Hirata, 1988, 1998; Kergoat, 1998).

A desigualdade da condição feminina tem sido crescentemente exposta pelos estudos feitos a partir de dados organizados pelos institutos de pesquisa nacionais e internacionais. Bruschini (1990), Jelin (1995), Duran (2000) e Sorj (2004), por exemplo, destacam a persistência de desigualdades e assimetrias de gênero nas formas de organização de vida familiar, em relação à distribuição das tarefas domésticas, ao envolvimento e responsabilidades com os cuidados com os membros da família. Essa assimetria se revela particularmente forte no conflito vivido pelas mulheres entre vida familiar e trabalho pago, sobretudo em se tratando de mulheres com cônjuge e filhos. Contudo, se há certo grau de consenso em relação aos traços centrais dessa interação, assim como em relação à característica multicausal das transformações, há também o reconhecimento das particularidades contextuais e da enorme diversidade na forma e na dinâmica dessas transformações (Milkman, Reese e Roth, 1998).

Recentemente, uma literatura crescente sobre economia e gênero tem buscado avançar no sentido de analisar esses temas. Ao reconhecer a importância da produção doméstica de bens e serviços não "mercantilizados", os economistas e outros cientistas sociais têm avançado na análise do trabalho reprodutivo. Por um lado, tem-se aprofundado a análise do trabalho exercido fora da esfera produtiva mercantil. Cabe-se destacar aqui os estudos sobre o uso do tempo, que, devido às restrições de estatísticas, se tornaram uma realidade muito recentemente. ${ }^{4}$

Por outro lado, têm-se expandido os estudos dedicados à análise de como as políticas públicas e as mudanças institucionais têm contribuído para reduzir a carga de trabalho não remunerado majoritariamente executado pelas mulheres. Isso se torna relevante devido, entre outros fatores, à crescente participação da mulher no mercado de trabalho produtivo, sem que haja como contrapartida uma redução proporcional e mais equitativa em relação aos homens na realização do trabalho reprodutivo. Essas análises se inserem em uma área relativamente nova da economia: a "economia do cuidado". Conforme definida por Espino (2006), ela pretende abordar um amplo 
espectro de bens, serviços, atividades, relações e valores que estão relacionados com a manutenção da existência humana e da reprodução social. ${ }^{5}$

\subsection{Mensuração do trabalho reprodutivo}

Um esforço necessário para se dar reconhecimento social às tarefas domésticas realizadas pelas mulheres consiste em atribuir um valor a essas atividades. ${ }^{6}$ O relatório da IV Conferência Mundial sobre a Mulher, organizada pela ONU em 1995 (UNDP, 1995), analisa o processo de exclusão feminina do desenvolvimento, mede a igualdade de gênero e oferece uma estratégia para buscar a equidade nas oportunidades entre mulheres e homens. Nas recomendações dessa conferência, foi explicitada a necessidade de incorporar a contribuição do trabalho não remunerado e realizado majoritariamente por mulheres em um sistema de contas satélites, como uma forma de dar visibilidade a essas tarefas, ocultas no recôndito dos lares. O Relatório também chama a atenção para a possibilidade de se fazer uma estimativa dessa contribuição (das tarefas domésticas/trabalho reprodutivo) para a renda nacional através de uma pesquisa sobre o tempo gasto por mulheres e homens em atividades mercantis e não mercantis. Propõe ainda que a mensuração da categoria trabalho passe a considerar o número de horas que as pessoas gastam fazendo as atividades domésticas (e não apenas o número de participantes na força de trabalho, como tradicionalmente é usual). ${ }^{7}$ A partir de então, houve uma proliferação dos estudos sobre o tempo como forma de subsidiar a tomada de decisões políticas e a gestão dos recursos humanos na sociedade, mas estes ainda são embrionários e estão longe de responder às demandas do movimento de mulheres. ${ }^{8}$

Em ensaio exploratório, Melo, Considera e Sabbato (2007) propõem uma valoração do trabalho reprodutivo a partir das estatísticas de tempo gasto com fazeres domésticos disponibilizados pelo IBGE desde 2001.

Os autores mostram, em primeiro lugar, a inconsistência dos argumentos utilizados para não-inclusão dos serviços domésticos não remunerados no Produto Nacional. De forma resumida, eles argumentam que o tratamento dado ao fator capital e ao fator trabalho é distinto. No caso do capital, todos os serviços considerados: toda a produção para autoconsumo da agricultura e a produção por conta própria de bens de capital fixo imobilizados pelo próprio produtor são, por exemplo, contabilizadas no produto 
nacional. Já no caso dos serviços do fator trabalho, em particular, dos serviços domésticos, apenas os remunerados são contabilizados. Ou seja, quando o trabalho doméstico é exercido por terceiros, seu valor equivale ao valor de sua remuneração. Entretanto, quando exercido por alguém da própria família, não é computado nas contas nacionais. Esse tratamento contrasta com o tratamento dado aos serviços do capital. Adicionalmente, do ponto de vista do mercado de trabalho, as pessoas que exercem apenas afazeres domésticos — as donas de casa sequer são consideradas como força de trabalho (PEA) - são classificadas como população inativa. Curiosamente, se estiverem exercendo, mesmo que sem remuneração, atividades em um empreendimento familiar, são tratadas como população ocupada.

Desde 2001, a Pesquisa Nacional por Amostra de Domicílios (PNAD) do IBGE investiga o número de horas despendido pela população na execução de afazeres domésticos ou trabalho reprodutivo. Esta resume da seguinte forma tais tarefas: arrumar ou limpar toda ou parte da moradia; cozinhar ou preparar os alimentos, passar roupa, lavar roupa ou louça, utilizando ou não aparelhos eletrodomésticos para executar essas tarefas para si ou para outro(s) morador(es); orientar ou dirigir trabalhadores domésticos na execução das tarefas domésticas; cuidar de filhos ou menores moradores (IBGE, 1992).

A partir da introdução dessa questão no corpo do questionário da PNAD, tornou-se possível realizar uma estimação do valor econômico do trabalho realizado no interior do domicílio pelos membros da família. Em sua estimativa, Melo, Considera e Sabbato (2007) atribuíram aos afazeres domésticos executados pelos membros da família gratuitamente a remuneração média horária dos serviços domésticos remunerados. A valoração dos afazeres domésticos foi feita de duas maneiras: i) considerando como rendimento médio do ano o rendimento médio dos trabalhadores do serviço doméstico remunerado registrado na PNAD referente ao mês de setembro, ${ }^{9}$ e ii) aplicando as variações mensais do salário mínimo ao longo do ano ao valor registrado pela PNAD em setembro. A mensuração da participação dos afazeres domésticos no PIB com os dois métodos é bastante próxima, sendo a diferença encontrada de apenas um ponto percentual para toda a série (Melo, 2008, e tabela 1).

Em termos monetários, a inclusão do valor dos afazeres domésticos nesse cálculo significaria acrescentar ao PIB de qualquer um dos anos considerados 
Tabela 1: Brasil - renda anual dos afazeres domésticos segundo diferentes métodos de cálculo, 2006

\begin{tabular}{lcc}
\hline Métodos & $\begin{array}{c}\text { Renda Anual } \\
\text { (R\$ Milhões Correntes) }\end{array}$ & 2006 \\
\hline Método 1 & 269.642 & 11,6 \\
\hline Método 2 & 240.011 & 10,3 \\
\hline Nota: & & \\
Método 1: renda semanal com afazeres domésticos multiplicada por 52 semanas; Método 2: renda semanal com afazeres \\
domésticos dividida pelo salário mínimo de setembro e multiplicada pela soma dos salários mínimos do ano. Para maiores \\
detalhes, ver Melo, Considera e Sabbato (2007) e Melo (2008). \\
Fonte: Melo, Considera e Sabbato (2007) e Melo (2008).
\end{tabular}

entre 2001 e 2006 aproximadamente 10 ou 11\%, dependendo do método de cálculo utilizado. Ou seja, esse valor não significa, de modo algum, uma quantia insignificante (tabela 1). Ademais, tal quantia é seguramente subestimada, pois se baseia nos rendimentos médios dos trabalhadores domésticos, que auferem os piores rendimentos femininos da sociedade brasileira (Melo et al., 2002; e Namir, 2006). A importância desse indicador econômico não precisa ser justificada, mas chamamos a atenção para o argumento feminista de que, como esse indicador fornece informações fundamentais para a elaboração de toda a política do estado, a omissão do trabalho reprodutivo desse cálculo contribui para tornar discriminatórias as políticas públicas seja ela relativa aos impostos, ao emprego, à seguridade social e aos serviços sociais relacionados à família e as crianças - e revela uma discriminação em relação às mulheres que realizam a maioria desses serviços.

\section{TRABALHO REPRODUTIVO: QUEM FAZ?}

Responder a essa pergunta é trivial. Quem executa os afazeres domésticos é naturalmente respondido pela sociedade: são as mulheres (donas de casa e suas empregadas domésticas), com auxílio de algumas pessoas do sexo masculino. Esse universo é naturalizado como feminino. Há um padrão de divisão sexual do trabalho que segmenta as atividades produtivas, vinculadas ao mercado, e as reprodutivas, relacionadas aos cuidados com os seres humanos, que vão além da maternidade como fator biológico e englobam todo o trabalho doméstico.

Nos últimos 30 anos, houve uma crescente inserção produtiva das mulheres no mundo do trabalho fora de casa. A taxa de atividade feminina em 
2005 atingiu cerca de 40\%, mas esse percentual indica que há um grande contingente de mulheres que permanece fora do mercado de trabalho: mais de 37 milhões de mulheres com mais de 10 anos de idade permanecem em suas casas, cuidando dos filhos, dos velhos, de familiares, dos doentes e do marido.

As informações indicam que os afazeres domésticos são exercidos tanto por homens quanto por mulheres, embora o número de mulheres e também o número de horas por elas dedicadas a essas atividades sejam bem superiores ao declarados pelos homens, como veremos adiante. Na prestação desses serviços não há folga: sábados e domingos são iguais, e mesmo as mulheres ocupadas no mercado de trabalho são também donas de casa. O trabalho doméstico não tem aposentadoria, as mulheres começam muito jovens e nunca deixam de fazê-lo. As mulheres com filhos pequenos acumulam essa atividade com as outras relativas à limpeza, cozinha, lavação. Claro que essas tarefas diminuem quando os(as) filhos(as) crescem e saem de casa, mas permanece a labuta, porque em cada domicílio ou família há um conjunto de tarefas essenciais à vida das pessoas e que devem ser realizadas por qualquer um dos membros da família. Mas, na maioria dos casos, elas são exercidas pelas mulheres.

Para uma detalhada medição dos afazeres domésticos, além de estabelecer o sexo, escolaridade e ocupação das pessoas ocupadas nessas tarefas, ${ }^{10}$ a PNAD deveria identificar os diferentes tipos de atividades domésticas e as remunerações específicas médias (por hora) de cada uma delas, para, em seguida, multiplicar essa variável pelo número de horas observado para cada tarefa doméstica. Mas esse indicador ainda não pode ser construído, porque a pesquisa amostral coleta somente os dados referentes ao número de horas gastas com afazeres em geral.

Uma análise da estrutura da população brasileira mostra, primeiramente, que a divisão sexual do trabalho é bem distinta para mulheres e homens, e isso está intimamente relacionado com o trabalho reprodutivo (tabela 2). Da população em idade ativa - PIA (população com 10 anos e mais) - de cerca de 152,7 milhões de pessoas em 2005, 52\% são mulheres e $48 \%$ homens. Esse saldo positivo feminino é explicado pela maior longevidade das mulheres. Quando se considera o trabalho produtivo, nota-se que a participação das mulheres no mundo da produção é bem diferente. Agora o indi- 
Tabela 2: População brasileira, 2005

\begin{tabular}{lccccc}
\hline & Homem & \multicolumn{2}{c}{ Mulher } & \multicolumn{2}{c}{ Total } \\
\hline & $\begin{array}{c}\text { Mil } \\
\text { pessoas }\end{array}$ & $\begin{array}{c}\text { Taxa de } \\
\text { participação } \\
(\%)\end{array}$ & $\begin{array}{c}\text { Mil } \\
\text { pessoas }\end{array}$ & $\begin{array}{c}\text { Taxa de } \\
\text { participação } \\
(\%)\end{array}$ & $\begin{array}{c}\text { Mil } \\
\text { pessoas }\end{array}$ \\
\hline População em Idade Ativa (PIA) & 73.795 & 48,3 & 78.945 & 51,7 & 152.740 \\
\hline População Economicamente Ativa (PEA) & 54.291 & 56,5 & 41.741 & 43,5 & 96.032 \\
\hline População Ocupada & 48.692 & 59,3 & 33.394 & 40,7 & 82.086 \\
\hline População Não Economicamente Ativa & 19.496 & 34,4 & 37.201 & 65,6 & 56.698 \\
\hline Fonte: IBGE, PNAD/BBGE. Elaboração própria. & & & & &
\end{tabular}

cador importante é a população economicamente ativa - PEA (ocupados e desempregados ou desocupados) - , que corresponde a 63\% da PIA total. Desse contingente, a taxa de participação masculina é de $59 \%$ e a feminina, de $41 \%$.

No restante da população em idade de trabalhar, mas que se encontra fora do mercado de trabalho - ou seja, 37\% da PIA ("população não economicamente ativa" ou inativos) —, a participação feminina também é bastante superior à sua participação na população total: elas representam 66\% do total contra $34 \%$ dos homens. Essa participação reflete o fato de que o percentual de mulheres inativas é bem superior ao percentual de homens inativos - $47 \%$ das mulheres em idade ativa estão fora do mercado de trabalho, enquanto, no caso dos homens, apenas $26 \%$ se encontram em situação semelhante. Esse indicador está intimamente relacionado ao trabalho reprodutivo, aquelas atividades ligadas à reprodução da vida. De fato, esse contingente da população feminina é majoritariamente formado pelas donas de casa, mulheres dedicadas aos cuidados da família - ou seja, ao que denominamos trabalho reprodutivo. A seguir, analisamos o perfil da população ocupada que declara realizar afazeres domésticos, para depois apresentarmos sucintamente o perfil da população inativa e, dessa forma, explicitar quem realiza essas tarefas na sociedade brasileira.

\subsection{0 "fazer" dos ocupados}

No que se refere ao universo dos ocupados, $68 \%$ dessa população realizam tarefas domésticas (tabela 3). O percentual de mulheres ocupadas que declaram realizar afazeres domésticos é, no entanto, muito superior ao percentual dos homens: 91\% das mulheres ocupadas declararam executar tarefas 
Tabela 3: Brasil - pessoal ocupado com 10 anos ou mais que realizam afazeres domésticos segundo sexo, 2005

\begin{tabular}{lccc}
\hline & Homem & Mulher & Total \\
\hline Pessoal total ocupado com & 48.692 .316 & 33.393 .903 & 82.086 .225 \\
mais de 10 anos de idade... & $59 \%$ & $41 \%$ & $100 \%$ \\
\hline ..e que declaram realizar algum & 25.009 .013 & 30.513 .781 & 55.522 .794 \\
tipo de afazeres domésticos & $45 \%$ & $55 \%$ & $100 \%$ \\
\hline \% do pessoal ocupado que declara & & & \\
realizar afazeres domésticos & $51 \%$ & $91 \%$ & $68 \%$ \\
\hline
\end{tabular}

Fonte: PNAD/BGGE. Elaboração própria.

domésticas para 51\% dos homens. Estas e estes têm uma dupla jornada de trabalho, expressão popularizada pelo movimento feminista desde os anos 1970. Mas veremos que a dupla jornada masculina é bem mais leve.

O número de mulheres que declaram realizar afazeres domésticos não somente é maior do que o número de homens como também a quantidade de horas dedicadas aos afazeres é bem superior no caso feminino. Enquanto a média declarada pelas mulheres é de 20,8 horas semanais, com uma forte concentração entre 10 e 30 horas semanais, a média declarada pelos homens é de 9,1 horas, com $89 \%$ deles declarando dedicar até 20 horas de trabalho aos afazeres domésticos (tabela 4).

Uma característica importante do trabalho reprodutivo é que ele é tão mais importante quanto menor for o grau de instrução dos trabalhadores, embora o volume médio de horas dedicado a afazeres domésticos mesmo para as mulheres mais escolarizadas seja mais do que o dobro de horas gastas pelos os homens com o mesmo grau de instrução (tabela 5). Essa diferença é maior no caso das mulheres do que no dos homens. Uma mulher sem instrução dedica em média 54\% a mais de tempo a afazeres domésticos do que os homens, enquanto a mesma comparação no caso masculino denota uma diferença de 37\%. Por consequência, o diferencial de horas médias dedicadas a afazeres entre mulheres e homens cai à medida que aumenta o grau de instrução de ambos.

Segundo a posição na ocupação (tabela 6), as categorias em que as mulheres despendem mais tempo com afazeres domésticos são aquelas nas quais há mais trabalho precário - ou seja, conta própria, sem remuneração e doméstica sem carteira. Nas duas primeiras ocupações, a razão entre a quantidade de horas gastas com afazeres domésticos declarada pelas mulhe- 
Tabela 4: Brasil - pessoal ocupado com 10 anos e mais que cuidava de afazeres domésticos segundo sexo e número de horas semanais com afazeres domésticos, 2005

\begin{tabular}{|c|c|c|c|c|c|c|c|}
\hline & \multicolumn{7}{|c|}{ Quantidade de horas semanais } \\
\hline & - de 5 & $\begin{array}{c}5 \mathrm{~A} \\
-\mathrm{de} 10\end{array}$ & $\begin{array}{c}10 \mathrm{~A} \\
-\mathrm{de} 20\end{array}$ & $\begin{array}{c}20 \mathrm{~A} \\
- \text { de } 30\end{array}$ & $\begin{array}{c}30 \mathrm{~A} \\
- \text { de } 40\end{array}$ & $\begin{array}{c}40 \\
\text { e mais }\end{array}$ & Total \\
\hline \multicolumn{4}{|l|}{ Número de pessoas } & \multicolumn{4}{|l|}{ Homem } \\
\hline ocupadas & 6.974 .073 & 8.008 .988 & 7.374 .307 & 2.100 .714 & 383.405 & 165.161 & 25.009 .013 \\
\hline que declararam & $28 \%$ & $32 \%$ & $29 \%$ & $8 \%$ & $2 \%$ & $1 \%$ & $100 \%$ \\
\hline \multicolumn{8}{|l|}{ realizar afazeres } \\
\hline domésticos por & \multicolumn{7}{|c|}{ Mulher } \\
\hline faixa de & 2.030 .902 & 3.785 .193 & 8.200 .285 & 8.994 .977 & 4.125 .704 & 3.373 .800 & 30.513 .781 \\
\hline tempo declarada & $7 \%$ & $12 \%$ & $27 \%$ & $29 \%$ & $14 \%$ & $11 \%$ & $100 \%$ \\
\hline Horas médias & \multicolumn{7}{|c|}{ Homem } \\
\hline dedicadas a & 2,6 & 6,6 & 12,3 & 21,7 & 31,7 & 46,2 & 9,1 \\
\hline \multicolumn{8}{|l|}{$\begin{array}{l}\text { afazeres } \\
\text { domésticos }\end{array}$} \\
\hline por faixa de & \multicolumn{7}{|c|}{ Mulher } \\
\hline tempo declarada & 2,9 & 6,7 & 13,1 & 22,7 & 32,2 & 47,5 & 20,8 \\
\hline
\end{tabular}

Fonte: PNAD/IBGE. Elaboração própria.

Tabela 5: Brasil - horas médias semanais dedicadas a afazeres domésticos do pessoal ocupado com 10 anos, segundo sexo e escolaridade, 2005

\begin{tabular}{lcc}
\hline Escolaridade (anos de estudo) & Homem & Mulher \\
\hline Zero & 10,28 & 24,80 \\
\hline 1 a 3 & 9,48 & 24,43 \\
\hline 4 a 7 & 9,16 & 23,09 \\
\hline 8 a 11 & 9,03 & 19,97 \\
\hline 12 e mais & 7,53 & 16,02 \\
\hline Não Ident. & 7,93 & 19,72 \\
\hline Total & 9,06 & 20,84 \\
\hline
\end{tabular}

Fonte: PNAD/IBGE. Elaboração própria.

Tabela 6: Brasil - horas médias semanais dedicadas a afazeres domésticos do pessoal ocupado com 10 anos e mais que cuidava de afazeres domésticos segundo sexo e posição na ocupação, 2005

\begin{tabular}{lcc}
\hline & Homem & Mulher \\
\hline Empregado c/ carteira & 8,59 & 17,09 \\
\hline Empregado s/ carteira & 9,16 & 19,52 \\
\hline Domést, c/ carteira & 11,58 & 18,88 \\
\hline Domést, s/ carteira & 10,61 & 22,32 \\
\hline Conta própria & 9,80 & 26,16 \\
\hline Empregador & 7,62 & 17,24 \\
\hline Militar & 7,92 & 10,76 \\
\hline Func, púb, estat, & 9,26 & 20,27 \\
\hline Sem remun, & 8,95 & 23,97 \\
\hline Total & 9,06 & 20,84 \\
\hline
\end{tabular}

Fonte: PNAD/IBGE. Elaboração própria. 
res é superior à média de todas as ocupações. Ou seja, enquanto o número médio de horas semanais trabalhadas pelas mulheres corresponde a 2,3 vezes o número de horas dedicadas pelos homens aos afazeres, para as mulheres que trabalham por conta própria ou sem remuneração essa razão sobe a 2,7 . As categorias em que as horas dedicadas a afazeres são menos díspares entre homens e mulheres são militares e empregados domésticos com carteira. Essa aparente igualdade, no entanto, ocorre justamente em dois setores bastante díspares em termos de participação masculina e feminina: dentre os militares a participação feminina é muito baixa e dentre os empregados domésticos a participação masculina é insignificante.

O número médio de horas dedicadas a afazeres domésticos varia bastante segundo as ocupações (tabela 7) e entre trabalhadores e trabalhadoras. As mulheres que mais executam tarefas domésticas são as trabalhadoras agrícolas, seguidas daquelas que trabalham em produção, reparação e manutenção de bens e serviços, vendedoras e prestadoras de serviços e trabalhadoras dos serviços. Essas categorias congregam as trabalhadoras de menor instrução, de acordo com o que foi mostrado na tabela 6. A categoria de trabalhadoras que declara despender menos tempo com afazeres domésticos é a de dirigentes, que têm maiores condições de pagar trabalhadores para realizar parte das atividades domésticas. Vale assinalar que, ainda assim, o diferencial de horas dedicadas a afazeres entre homens e mulheres que desempe-

Tabela 7: Brasil - Horas médias semanais dedicadas a afazeres domésticos do pessoal ocupado com 10 anos ou mais segundo sexo e grupo ocupacional, 2005

\begin{tabular}{lcc}
\hline & Homem & Mulher \\
\hline Trabalhadores agrícolas & 9,38 & 25,04 \\
\hline Trabalhadores da produção de bens e serviços & 8,93 & 22,35 \\
e de reparação e manutenção & & \\
\hline Vendedores e prestadores de serviço do comércio & 9,34 & 22,13 \\
\hline Trabalhadores dos serviços & 10,39 & 22,07 \\
\hline Técnicos de nível médio & 8,48 & 19,61 \\
\hline Membros das forças armadas e auxiliares & 9,24 & 18,09 \\
\hline Profissionais das ciências e das artes & 7,97 & 17,59 \\
\hline Trabalhadores de serviços administrativos & 8,41 & 16,45 \\
\hline Dirigentes em geral & 7,44 & 15,95 \\
\hline Ocupações mal definidas ou não declaradas & 7,85 & 12,80 \\
\hline Total & 9,06 & 20,84 \\
\hline
\end{tabular}

Fonte: PNAD/BGE. Elaboração própria. 
nham funções de direção ainda é bastante elevado, as mulheres dedicando em média 2,14 vezes o tempo que os homens dedicam. Porém, é entre os trabalhadores e as trabalhadoras agrícolas que a diferença de horas dedicadas a afazeres domésticos é mais elevada: mulheres dessa categoria dedicam 2,67 vezes o tempo dedicado pelos homens para afazeres domésticos.

A análise da distribuição por setores de atividades das mulheres que declaram realizar afazeres mostra que esta se assemelha bastante à distribuição setorial do trabalho produtivo (tabela 8). Isso se deve ao elevado percentual de mulheres que declaram realizar esse tipo de atividade - $91 \%$ das mulheres ocupadas declaram realizar afazeres domésticos, contra um percentual bem inferior no caso dos homens (51\%), conforme a tabela 3. Os setores que absorvem maiores parcelas do trabalho feminino são das atividades de serviços - comércio e serviços prestados às famílias, comércio e administração pública, como pode ser visto na tabela 8 . Grande parte das mulheres empregadas nesses setores tem dupla jornada de trabalho: cerca de $90 \%$ delas declaram realizar afazeres domésticos. Deve-se destacar a situação vivida pelas mulheres rurais, que, quase em sua totalidade, declaram ter obrigações domésticas.

O percentual de homens declarantes é bastante inferior ao das mulheres, como atesta sua média (51\%) e o fato de que, em apenas dois setores (pouco representativos em termos de volume de emprego) - aluguel de imóveis e outros - , mais de $60 \%$ deles declaram realizar afazeres domésticos. Vale assinalar ainda que, embora o número absoluto de declarantes seja elevado em setores como agricultura e comércio, o número de declarantes relativamente ao número de ocupados é inferior à média masculina (48,9\% e 48,3\%, respectivamente).

\subsection{0 "fazer" dos inativos}

A fim de avaliar a extensão do trabalho reprodutivo realizado pelo conjunto da população adulta, analisamos a seguir se as pessoas que não estão no mundo do trabalho dedicam um número maior de horas ao trabalho reprodutivo e quais as diferenças entre os sexos no que se refere ao tempo dedicado a afazeres domésticos. Nos levantamentos censitários, a categoria "inativos" compreende os indivíduos que não trabalham, aposentados, rentistas, estudantes, inválidos ou doentes e as pessoas que se dedicam exclusivamen- 
Tabela 8: Brasil - distribuição setorial das pessoas ocupadas que declaram realizar afazeres domésticos, 2005

\begin{tabular}{|c|c|c|c|c|c|c|}
\hline \multirow[b]{2}{*}{ Setor } & \multicolumn{3}{|c|}{ Homem } & \multicolumn{3}{|c|}{ Mulher } \\
\hline & $\mathrm{N}^{\circ}$ pessoas & $\begin{array}{c}(\%) \text { no total } \\
\text { de } \\
\text { declarantes (1) }\end{array}$ & $\begin{array}{c}\text { Peso no } \\
\text { total } \\
\text { ocupado }\end{array}$ & No pessoas & $\begin{array}{c}(\%) \text { no total } \\
\text { de } \\
\text { declarantes (1) }\end{array}$ & $\begin{array}{c}\text { Peso no } \\
\text { total } \\
\text { ocupado }\end{array}$ \\
\hline Agropecuária & 5.116 .845 & 20,5 & 48,9 & 2.840 .101 & 9,3 & 98,0 \\
\hline Extrativa Mineral & 104.735 & 0,4 & 42,2 & 17.273 & 0,1 & 81,1 \\
\hline Extração de Petróleo e Gás & 20.382 & 0,1 & 45,9 & 3.023 & 0,0 & 87,2 \\
\hline Minerais não Metálicos & 246.509 & 1,0 & 44,8 & 71.280 & 0,2 & 86,7 \\
\hline Siderurgia e Metalurgia & 519.219 & 2,1 & 54,6 & 90.564 & 0,3 & 88,7 \\
\hline Máquinas e Tratores & 273.305 & 1,1 & 53,3 & 64.363 & 0,2 & 89,1 \\
\hline Material Elétrico e Eletrônico & 209.239 & 0,8 & 56,7 & 148.702 & 0,5 & 86,9 \\
\hline Material de Transporte & 289.445 & 1,2 & 55,8 & 73.455 & 0,2 & 84,5 \\
\hline Madeira e Mobiliário & 504.179 & 2,0 & 51,5 & 129.463 & 0,4 & 94,3 \\
\hline Papel e Gráfica & 219.166 & 0,9 & 52,3 & 135.862 & 0,4 & 86,2 \\
\hline Indústria da Borracha & 53.210 & 0,2 & 58,1 & 14.021 & 0,0 & 93,9 \\
\hline Indústria Química & 225.693 & 0,9 & 54,0 & 83.595 & 0,3 & 89,2 \\
\hline Refino do Petróleo & 16.826 & 0,1 & 58,9 & 4.459 & 0,0 & 56,9 \\
\hline Farmacêutica e Perfumaria & 77.348 & 0,3 & 48,4 & 104.548 & 0,3 & 89,1 \\
\hline Artigos de Plástico & 108.326 & 0,4 & 55,7 & 63.079 & 0,2 & 94,3 \\
\hline Indústria Têxtil & 150.884 & 0,6 & 59,7 & 576.984 & 1,9 & 96,7 \\
\hline Artigos do Vestuário & 146.318 & 0,6 & 52,3 & 1.342 .093 & 4,4 & 94,3 \\
\hline Fabricação de Calçados & 248.797 & 1,0 & 57,4 & 356.720 & 1,2 & 95,5 \\
\hline Produtos Alimentares & 639.043 & 2,6 & 50,1 & 770.388 & 2,5 & 94,7 \\
\hline Indústrias Diversas & 115.326 & 0,5 & 54,8 & 249.952 & 0,8 & 95,8 \\
\hline Serv. Industriais de Utilidade Pública & 243.698 & 1,0 & 54,8 & 86.235 & 0,3 & 86,8 \\
\hline Construção Civil & 2.733 .299 & 10,9 & 50,8 & 111.828 & 0,4 & 86,2 \\
\hline Comércio & 4.632 .759 & 18,5 & 48,3 & 5.263 .764 & 17,3 & 89,4 \\
\hline Comércio, Transportes & 1.459 .466 & 5,8 & 47,6 & 277.337 & 0,9 & 86,8 \\
\hline Comércio, Comunicações & 242.221 & 1,0 & 52,0 & 205.279 & 0,7 & 81,5 \\
\hline Comércio, Instituições Financeiras & 257.967 & 1,0 & 51,7 & 398.252 & 1,3 & 79,2 \\
\hline Comércio, Serv. Prest. às Famílias & 2.086 .242 & 8,3 & 54,8 & 10.562 .797 & 34,6 & 91,4 \\
\hline$\underline{\text { Comércio, Serv. Prest. às Empresas }}$ & 1.504 .844 & 6,0 & 57,7 & 1.194 .164 & 3,9 & 86,1 \\
\hline Aluguel de Imóveis, Comércio & 343.141 & 1,4 & 64,1 & 150.403 & 0,5 & 89,1 \\
\hline Administração Pública & 1.924 .986 & 7,7 & 56,2 & 4.550 .717 & 14,9 & 91,5 \\
\hline Outros & 295.595 & 1,2 & 61,1 & 573.080 & 1,9 & 92,4 \\
\hline TOTAL & 25.009 .013 & 100,0 & 51,4 & 30.513 .781 & 100,0 & 91,4 \\
\hline
\end{tabular}

Notas: (1) Que declaram realizar afazeres domésticos. Fonte: PNAD/IBGE. Elaboração própria. 
te aos afazeres domésticos - as donas de casa. A execução das tarefas domésticas - trabalho reprodutivo - não é contabilizada como atividade econômica pelas razões já explanadas neste trabalho, mas interessa ao escopo deste estudo ter uma dimensão do viés de gênero que apresenta a suposta "inatividade".

A tabela 9 mostra a população com 10 anos ou mais que declararam realizar afazeres domésticos em 2005, distinguindo aquela que se encontra fora (inativos) e dentro da PEA (desocupados e ocupados). A população considerada inativa é quase $66 \%$ composta por mulheres. Do contingente feminino de inativas, 97\% declararam realizar afazeres domésticos. Esse percentual é um pouco mais elevado do que os $91 \%$ das mulheres ocupadas que realizam afazeres e, sobretudo, muito superior ao percentual de homens inativos que declaram realizar atividades domésticas (53\%). De qualquer maneira, na categoria "inativos" ambos os sexos apresentam uma taxa de participação ligeiramente superior de ocupação com afazeres domésticos.

Observem que 30\% dessas mulheres (donas de casa) fazem mais de 40 horas de trabalhos domésticos semanais, enquanto os homens na mesma situação são apenas 3\% (tabela 10). Essa discrepância entre homens e mulheres é mais acentuada para homens e mulheres inativos do que homens e mulheres ocupados, dentre os quais $11 \%$ dessas mulheres realizam mais de 40 horas semanais de trabalhos domésticos para apenas $0,6 \%$ dos homens. ${ }^{11}$ A situação é invertida para as jornadas de afazeres domésticos mais baixas — de até 20 horas semanais _, em que os homens apresentam maiores concentrações contra participações insignificantes das mulheres.

O número de horas médias por faixa de jornadas de trabalho reprodutivo reforça a disparidade ressaltada. Em todas as faixas, a média de horas dedicadas a afazeres pelas mulheres é superior à dos homens, sendo o diferencial para o conjunto de mulheres inativas relativamente ao conjunto de homens inativos bastante elevado - 11,1 horas semanais para os homens contra 28,5 para as mulheres.

Essas diferenças são reproduzidas para todas as posições na ocupação. Em 2005, os homens brasileiros realizaram jornadas de afazeres domésticos que variaram de 11,1 horas semanais para os inativos, 12,7 horas para os desempregados e 9,1 horas para os ocupados, enquanto as mulheres declararam 28,5 horas para as inativas, 28,6 horas para as desempregadas e 20,8 
Tabela 9: Brasil - população que declara realizar afazeres domésticos segundo atividade e sexo, 2005

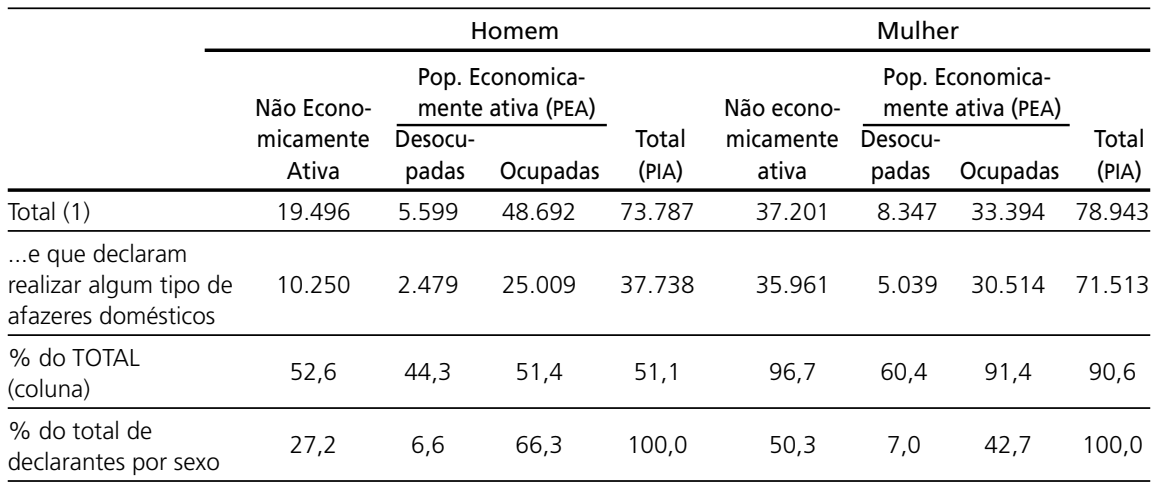

Notas: (1) Pessoas de 10 anos ou mais de idade. Fonte: IBGE e PNAD/BGE. Elaboração própria.

Tabela 10: Brasil - pessoal inativo com 10 anos e mais que cuidava de afazeres domésticos segundo sexo e número de horas semanais com afazeres domésticos, 2005

\begin{tabular}{|c|c|c|c|c|c|c|c|}
\hline & \multicolumn{7}{|c|}{ Quantidade de horas semanais } \\
\hline & - de 5 & $5 \mathrm{a}-$ de 10 & 10 a - de 20 & $20 \mathrm{a}-$ de 30 & $30 \mathrm{a}-\mathrm{de} 40$ & 40 e mais & Total \\
\hline $\mathrm{N}^{\circ}$ pessoas ocupadas & \multicolumn{7}{|c|}{ Homem } \\
\hline que declararam & 2.461 .091 & 2.992 .084 & 2.989 .879 & 1.225 .214 & 311.730 & 269.651 & 10.249 .859 \\
\hline realizar afazeres & $24 \%$ & $29 \%$ & $29 \%$ & $12 \%$ & $3 \%$ & $3 \%$ & $100 \%$ \\
\hline domésticos por & \multicolumn{7}{|c|}{ Mulher } \\
\hline faixa de & 1.937 .049 & 3.436 .664 & 6.571 .235 & 7.727.778 & 5.633 .081 & 10.643.417 & 35.960 .69 \\
\hline tempo declarada & $5 \%$ & $10 \%$ & $18 \%$ & $21 \%$ & $16 \%$ & $30 \%$ & $100 \%$ \\
\hline \multicolumn{8}{|l|}{ Horas médias } \\
\hline dedicadas a & \multicolumn{7}{|c|}{ Homem } \\
\hline afazeres 2.5 & 6,6 & 12,4 & 22,2 & 32,1 & 49,4 & 11,1 & \\
\hline domésticos & \multicolumn{7}{|c|}{ Mulher } \\
\hline $\begin{array}{l}\text { por talxa de } \\
\text { tempo declarada }\end{array}$ & 2,7 & 6,7 & 13,1 & $\begin{array}{c}\text { Mulner } \\
23,1\end{array}$ & 32,6 & 51,5 & 28,5 \\
\hline
\end{tabular}

Fonte: PNAD/BGE. Elaboração própria.

Tabela 11: Brasil - horas médias semanais dedicadas a afazeres domésticos do pessoal inativo com 10 anos segundo sexo e escolaridade, 2005

\begin{tabular}{lll}
\hline Escolaridade (anos de estudo) & Homem & Mulher \\
\hline Zero & 13,34 & 30,60 \\
\hline 1 a 3 & 10,72 & 27,55 \\
\hline 4 a 7 & 10,25 & 26,80 \\
\hline 8 a 11 & 11,68 & 30,75 \\
\hline 12 e mais & 12,29 & 26,55 \\
\hline Não ident. & 11,10 & 32,47 \\
\hline Total & 11,07 & 28,49 \\
\hline
\end{tabular}

Fonte: PNAD/IBGE. Elaboração própria. 
para as ocupadas. É interessante observar que as mulheres ocupadas têm uma queda na jornada de afazeres domésticos mais significativa que os homens, ou seja, mesmo empregados eles dedicam o mesmo pouco tempo que dedicam quando fora do mercado de trabalho às tarefas domésticas.

Para as mulheres inativas, a jornada de trabalho com afazeres domésticos não é muito díspar segundo o grau de escolaridade, sem que nenhuma relação clara entre quantidade de anos de estudo e de trabalho reprodutivo seja evidente. Claro, permanece a diferença entre os sexos, mas a variação entre analfabetas e aquelas com educação superior é pequena, sendo as mulheres com entre 1 e 11 anos de estudo aquelas com maior diferencial em relação aos homens (tabela 11). Na realidade essas tarefas são executadas para que a vida se reproduza, e independentemente da escolaridade todas têm de realizá-las.

Apesar de não mostrarmos aqui, as mulheres desempregadas dedicam cerca do mesmo tempo aos afazeres domésticos — para o conjunto delas, a média de horas dispensadas com afazeres é de 28,6. Já para os homens desempregados, a média é de 12,7 horas semanais. Vale assinalar que as mulheres, quando fora do mercado de trabalho — inativas ou desempregadas — , dedicam em média $37 \%$ de tempo a mais para tarefas domésticas. Já no caso dos homens, esse aumento é de $22 \%$ no caso dos inativos e $40 \%$ no caso dos desempregados (relativamente aos ocupados).

\section{CONCLUSÕES}

A perspectiva de gênero no estudo das relações sociais possibilitou a emergência de uma forma mais consistente de analisar os papéis sociais das mulheres e homens na sociedade, apreendendo as desigualdades e desenvolvendo como um de seus componentes analíticos centrais a assimetria de poder na sociedade.

Este estudo pretende contribuir para a discussão do papel das atividades relativas ao bem-estar humano e às necessidades das pessoas, destacando-se as diferenças relativas aos papéis femininos e masculinos. Nessa perspectiva de gênero está, evidentemente, compreendida a produção mercantil de bens e serviços. Porém, esse é apenas um dos aspectos da questão; os demais, incluindo as atividades relacionadas à reprodução da vida realizadas fora da 
esfera mercantil, foram - e ainda são - negligenciados tanto pela economia, como pela sociologia e a política. Ao privilegiar a produção mercantil de bens e serviços, esses campos disciplinares esqueceram-se de todas as demais atividades (materiais e imateriais) dirigidas ao bem-estar emocional das pessoas, particularmente o trabalho familiar doméstico realizado majoritariamente pelas mulheres. O conceito de divisão sexual do trabalho consolidou a subestimação das atividades realizadas pelas mulheres na família. Essa percepção contribui para que seja feita uma associação linear entre a atividade masculina e a produção mercantil e a feminina e a atividade familiar doméstica; estas veladas pela sociedade, consequentemente desvalorizadas. Eis a raiz do papel subalterno feminino.

Colocar essa questão na agenda política da sociedade é uma luta do movimento feminista internacional e nacional, e essa tarefa começa pela valoração do que está esquecido e escondido socialmente. Como mostramos, a mensuração dos afazeres domésticos na sociedade brasileira mostra que, mantendo todas as condições sine qua non, os afazeres domésticos realizados pelos homens e pelas mulheres majoritariamente agregam cerca de 12\% ao PIB brasileiro no ano 2006.

Como as mulheres trabalham duplamente - elas estão crescentemente envolvidas no trabalho produtor de mercadorias e são, aparentemente, insubstituíveis no trabalho reprodutivo - dedicamo-nos a mostrar as diferenças de volume e do perfil de homens e mulheres que executam os trabalhos domésticos.

As mulheres que declaram realizar algum tipo de afazer doméstico são mais numerosas, representam uma maior parcela da força de trabalho e dedicam em média bem mais horas do que os homens a esse tipo de trabalho, independentemente do nível de instrução, da posição na ocupação, do grupo ocupacional e do setor produtivo no qual estão inseridas. As mulheres dedicam, em média, entre duas e três vezes o tempo dedicado pelos homens às tarefas domésticas, essa diferença sendo mais elevada quando homens e mulheres saem do mercado de trabalho. Em suma, os afazeres domésticos são pesadamente uma incumbência feminina.

Dar visibilidade a essas questões é, sem dúvida, importante para o movimento feminista. Porém, as informações disponíveis nas estatísticas oficiais ainda são insuficientes. Os dados sobre os afazeres domésticos são agrega- 
dos e não sabemos exatamente o que é o "trabalho doméstico" de cada um. Esse trabalho pode englobar as tarefas mais variadas, tais como lavar, passar, cozinhar, varrer, levar criança à escola etc. O ideal seria conhecê-las a fim, entre outros, de verificar se os homens e as mulheres fazem indistintamente as mesmas tarefas ou se, a exemplo do que ocorre no mercado de trabalho produtivo, há uma clara divisão de atribuições e funções.

\section{NOTAS}

1. O conceito de gênero é um dos principais instrumentais teóricos utilizados pela produção acadêmica feminista. Ele é definido por uma de suas mais relevantes teóricas, Joan Scott (1994), como “organização social da diferença social”. Apesar da unanimidade sobre o significado da categoria gênero, há inúmeras críticas relativas à despolitização que seu uso imprimiu aos estudos feministas acadêmicos e à ação pública. Não há uma homogeneidade nessas visões, até porque o movimento de mulheres diversificou-se e é plural (ver, por exemplo, Lima Costa, 1998, e Paulilo, 2004). No Brasil, o desenvolvimento do conceito de gênero surge no início dos anos 1980, no rastro do fortalecimento da luta feminista nacional, ganhando espaço no campo da ação política do estado ao longo do tempo. Esse enfoque ainda na atualidade continua sendo uma das principais referências analíticas propostas pelos feminismos dos anos 1970 no mundo e no Brasil.

2. Ver Therborn (2006) e Castells (2000).

3. Os pioneiros estudos sobre a divisão sexual do trabalho, ver André Michel (1977).

4. No Brasil, os estudos sobre o uso do tempo disponíveis são Aguiar (2001), Dedecca (2005) e Soares (2008).

5. Dentre essas atividades, encontram-se aquelas relacionadas às esferas de reprodução e manutenção da mão-de-obra, que incluem não somente o trabalho doméstico não remunerado, como também a provisão dos ditos serviços de cuidado, seja por entes públicos, seja por entes privados (para maiores detalhes, ver Floro, 1995; Cagatay, 2005; ou Aguirre, García Sainz e Carrasco, 2005).

6. Segundo Walker (1977), em 1973, a Associação Americana de Economia Doméstica realizou uma demanda à Comissão Econômica Interparlamentar do Congresso dos Estados Unidos de valoração dos serviços domésticos. Esse mesmo autor relata que, em 1973, os economistas Tobin e Nordlaus propuseram uma medida de bem-estar intitulada MEW (Measure of Economic Welfare), rebatizada por Paul Samuelson de NEW (Net Economic Welfare), ambas incluindo um valor atribuído às tarefas domésticas executadas pelas donas de casa e o trabalho "produtivo" efetuado pelos maridos na moradia.

7. Notem que não há empecilhos técnicos para essa questão, e como exemplo podemos citar o caso da cidade de Buenos Aires, que, em 2003, aprovou uma lei para promover uma pesquisa sistemática para quantificar o aporte econômico realizado pelas donas de casa daquela cidade (Consejo Nacional de la Mujer, 2005). 
8. Ver, por exemplo, Duran, 2000; Aguiar, 2001; Aguirre et al., 2005; Dedecca, 2004, 2005; Soares, 2008; e Guryan, et al., 2008.

9. A utilização do mês de setembro é devido a que é nesse mês que essa pesquisa amostral vai a campo.

10. Essas informações são coletadas desde 2001.

11. Nossos cálculos mostram que os desempregados também seguem a mesma lógica e, nem por estarem sem ocupação no momento da pesquisa, aumentaram sua jornada de afazeres em face dos aos ocupados.

\section{REFERÊNCIAS BIBLIOGRÁFICAS}

AGUIAR, N. Múltiplas temporalidades de referência: trabalho doméstico e trabalho remunerado em uma plantação canavieira. Revista Gênero, Núcleo Transdisciplinar de Estudos de Gênero (Nuteg) da Universidade Federal Fluminense, v. 1, n. 2, 1. sem., 2001.

- Gênero e Ciências Humanas — desafio às ciências desde a perspectiva das mulheres. Rio de Janeiro: Rosa dos Tempos/Record, 1997.

AGUIRRE, R.; GARCÍA S., C.; CARRASCO, C. El tiempo, los tiempos, una vara de desigualdad. Serie Mujer y Desarrollo Cepal, Santiago, n. 65, 2005.

BEAUVOIR, S. O Segundo Sexo. 2. ed. Rio de Janeiro: Nova Fronteira, 1980, 2 v. (Primeira edição francesa de 1949 de Editions Gallimard.)

BOSERUP, E. Women's role in Economic Development. Nova York: Saint Martin's Press, 1970.

BRUSCHINI, C. Mulher, casa e família. São Paulo: FCC e Vértice, 1990.

CAGATAY, N. Theoretical approaches to gender and trade. Utah: Economics Department, University of Utah, 2005. (mimeo.)

CASTELLS, M. O Poder da identidade. Rio de Janeiro: Paz e Terra, 2000.

CONSEJO NACIONAL DE LA MUJER. Decir MUJER es decir trabalo - Metodologias para la medición del uso del tiempo con perspectiva de género. Argentina: Consejo Nacional de la Mujer, Embajada de España en Argentina, Agencia Española de Cooperación Internacional (Orgs.), 2005.

COSTA, C. O tráfico do gênero. Cadernos Pagu, n. 11, 1998.

DEDECCA, C. Tempo, trabalho e gênero. In: COSTA, A. A.; OLIVEIRA, E. M. DE; LIMA, M. E. B. DE; SOARES, V. (Orgs.). Reconfiguração das relações de gênero no trabalho. São Paulo: Cut, 2004.

DEDECCA, C. Sobre tempos e gênero na sociedade brasileira. Trabalho preparado para a Unifem, 2005. (mimeo.)

DURAN, M. A. Uso del tiempo y trabajo no remunerado. Revista de Ciencias Sociais, n. 18, p. 56-69, 2000.

ESPINO, A. Comercio, género y equidad en América Latina: generando conocimiento para la acción política. Montevidéu: Projeto de pesquisa, IGTN-LA/IRDC, 2006. 
FLORO, M. Economic restructuring, gender and the allocation of time. World-Development, v. 23, n. 11, p. 1913-1929, 1995.

GURYAN, J.; HURST, E.; KEARNEY, M. Parental education and parental time with children. Economic Perspectives, v. 22, n. 3, Summer, 2008.

HIRATA, H. Reestruturação produtiva, trabalho e relações de gênero. In: Gênero, Tecnologia e Trabalho: Revista Latinoamericana de Estudos do Trabalho - Associação Latino-americana de Sociologia do Trabalho. Rio de Janeiro, ano 4, n. 7, 1998.

. Divisão social e processo de trabalho na sociedade japonesa. Estudos Japoneses: Revista do Centro de Estudos Japoneses da Universidade de São Paulo, São Paulo, v. 8, p. 35-42, 1988.

IBGE - INSTITUTO BRASILEIRO DE GEOGRAFIA E ESTATÍSTICA. Sistemas de Contas Nacionais Brasil, 1990-1995, 1997, v. 1; PNAD, 1992, e microdados de 2002/06.

JELLIN, E. Família y Gênero: notas para el debate. Revista Estudos Feministas, v. 3, n. 2, p. 394413, 1995.

KERGOAT, D. La division du travail entre les sexes. In: KERGOAT, J. et al. (Orgs.). Le Monde du Travail. Paris: La Découverte, 1998.

LIMA C. C. O tráfico do gênero. Cadernos Pagu, n. 11, p. 127-140, 1998.

MELO, H. P. DE. Brasil, a invisibilidade do trabalho feminino. Texto apresentado pela Secretaria Especial de Políticas para as Mulheres na III Cúpula — IBAS, Divisão do Fórum de Diálogo Índia, Brasil e África do Sul, Nova Delhi, 11/15 out. 2008.

MELO, H.; CONSIDERA, C.; SABBATO, A. Os afazeres domésticos contam. Economia e Sociedade, Revista do Instituto de Economia da Unicamp, v. 16, n. 3, 2007.

; PESSANHA, M. C.; PARREIRAS, L. E. Da cozinha para o mercado: a evolução dos rendimentos dos trabalhadores domésticos nos anos 90. In: GALEAZZI, I. M. S. Mulher e trabalho. Porto Alegre: FEE, FGTAS/SINE, DIEESE, SEADE/SP, FAT. 2002.

; SABBATO, A.; SOUZA, C. F.; ROCHA, F.; FERRAZ, G.; HORTA, M. H. DWECK, R. H.; WADDINGTON, S. Os serviços no Brasil, Brasília, Ministério da Indústria, do Comércio e do Turismo. IPEA, ANPEC, 1998.

; SERRANO, F. A mulher como objeto da teoria econômica. In: AGUIAR, N. Gênero e Ciências Humanas — desafio às ciências desde a perspectiva das mulheres. Rio de Janeiro: Rosa dos Tempos/Record, 1997.

PENA, M. V. A condição feminina e a teoria Econômica. Literatura Econômica, IPEA, fev. 1985.

MICHEL, A. Femmes, Sexisme et Sociétés. Paris: Presses Universitaires de France (PUF). 1977.

MILKMAN, R.; REESE, E.; ROTH, B. A macrossociologia do trabalho doméstico remunerado. Revista Latinoamericana de Estudios del Trabajo/Revista Latino-Americana de Estudos do Trabalho, ano 4, n. 7, 1998.

NAMIR, K. Perfil dos trabalhadores domésticos no Brasil metropolitano. Revista Gênero, v. 7 e $8,2006$. 
PAULILO, M. Trabalho familiar: uma categoria esquecida de análise. Revista Estudos Feministas, CFC/CCE/UFSC, v. 12, n. 1, 2004.

SORJ, B. Reconciling work and family: issues and policies in Brazil. Conditions of Work and Employment Series. Geneva: International Labour Office, n. 8, 2004.

SCOTT, J. Gender and the Politics of History. Nova York: Columbia University Press, 1994.

SOARES, C. A distribuição do tempo dedicado aos afazeres domésticos entre homens e mulheres no âmbito da família. Encontro Nacional de Estudos Populacionais, 16. Associação Brasileira de Estudos Populacionais (ABEP). Anais. Caxambu, MG, 29/09 a 03/10, 2008.

UN. SYSTEM OF NATIONAL ACCOUNTS. A Conta de Produção. Nova York: United Nations, 1993. cap. IV.

UNDP. Human development report 1995. Nova York: Oxford University Press, 1995.

THERBORN, G. Sexo e Poder. São Paulo: [s.n.], 2006. 